\title{
Toxicodependência na gravidez e maternidade - a importância de uma abordagem multidisciplinar
}

Cristina Nunes, ${ }^{*}$ Susana Rocha, ${ }^{* *}$ Tânia Esteves***

\section{RESUMO}

Introdução: Os problemas de adição na gravidez e na maternidade são graves. Em particular, o uso de cannabis não é inofensivo. Pode estar associado a uma síndrome de abstinência no recém-nascido e alterações do desenvolvimento na criança mais velha.

O artigo descreve a abordagem multidisciplinar no caso de toxicodependência na gravidez, fornecendo algumas pistas para ajudar os médicos de família a lidar com as crianças afectadas e a aumentar o interesse sobre o tema da toxicodependência na relação mãe-filho.

Descrição do caso: Apresenta-se o caso de uma mulher grávida, seropositiva para o VIH, consumidora de cannabis. A gravidez foi não planeada mas desejada e vigiada. $O$ filho resultante desta gravidez apresenta um atraso de desenvolvimento psicomotor de cerca de 3 a 6 meses correspondente à sua idade real. Foi analisado o caso com a sua Médica de Família, em conjunto com a Pediatra e a Assistente Social.

Comentário: A abordagem destes casos deve ser multidisciplinar, através de referenciação atempada. $O$ tratamento de suporte é sempre adequado e deve ser instituído precocemente. Promovendo um ambiente familiar funcional e com a vigilância da Comissão de Protecção de Menores, as intervenções educativas precoces durante a gravidez e nos primeiros meses e anos de vida da criança são das mais valiosas para um desenvolvimento o mais pleno possível. Este tipo de cuidados está ao alcance do Médico de Família.

Palavras-chave: Comportamento Aditivo; Síndrome de Abstinência Neonatal; Intervenção Precoce; Cannabis.

\section{INTRODUÇÃO}

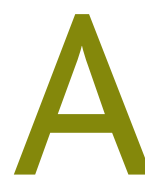
toxicodependência é um problema grave na sociedade. Encontra-se associada a elevada morbilidade, disfunção familiar e dificuldades laborais e sócio-económicas. ${ }^{1}$ Os problemas de adição incrementam na gravidez e na maternidade. Em particular, o uso de cannabis produz alguns efeitos a curto e longo prazo, ligeiros a moderados, tanto na grávida como no futuro filho, a nível de memória, aprendizagem, pensamento, percepção e coordenação motora, que a tornam não tão inofensiva como poderia parecer. ${ }^{2,3} \mathrm{~A}$ vulnerabili-

*Assistente de Medicina Geral e Familiar, Unidade de Saúde da Buraca, ACES VII da Amadora

**Assistente Hospitalar de Pediatria, Hospital de Nossa Senhora do Rosário, Centro Hospitalar do Barreiro-Montijo

***Assistente Social, ACES VII da Amadora dade associada à toxicodependência amplifica-se quando nasce um filho, um acontecimento de vida que exige a concentração de esforços dos pais e da comunidade, habitualmente distantes neste contexto. ${ }^{4}$

A toxicodependência na maternidade é um tema pouco abordado no âmbito da Medicina Geral e Familiar, pois é uma situação muito específica que pode parecer estar reservada em exclusivo para a Neonatologia ePediatria. Defacto, logo após o parto o recém-nascido pode manifestar uma síndrome de abstinência e o seu tratamento farmacológico poderá ser considerado em casos seleccionados, neste caso pela Pediatria intra-hospitalar. ${ }^{5}$ Contudo, por outrolado a terapêutica não farmacológica na abstinência, apelidada de tratamento de suporte, é sempre adequada e deve ser instituída precocemente, de forma intensiva, através de uma 
abordagem multidisciplinar. ${ }^{5}$ Como se poderá verificar, está ao alcance do médico de família reforçar e mesmo coordenar alguns destes cuidados ao recém-nascido após a alta hospitalar. Para o filho de mãe adicta, as intervenções educativas precoces durante a gravidez e nos primeiros meses e anos de vida da criança são relevantes para um desenvolvimento o mais pleno possível. ${ }^{6} \mathrm{~A}$ criança deve ser encaminhada na idade pré-escolar, pois grande parte das aprendizagens e do desenvolvimento ocorre mais rapidamentenessa altura. Mais tarde, a criança, sendo mais velha, perde oportunidades de desenvolvimento.

Pretende-se com este trabalho ilustrar a plêiade de problemas associados à toxicodependência na gravidez e maternidade, realçando a importância de uma abordagem multidisciplinar na orientação destes casos.

Esperemos que a apresentação deste caso forneça algumas pistas para ajudar os médicos de família a lidar com estas crianças e a aumentar o interesse sobre o tema da toxicodependência na relação mãe-filho.

\section{DESCRIÇÃO DO CASO}

Contexto familiar: Judite (nome fictício), 27 anos de idade, caucasiana, nasceu e reside no Concelho de Lisboa. Possui o $12 .^{\circ}$ ano de escolaridade e tem empregos temporários na área da estética (de momento tem um contrato de trabalho de 6 meses). Actualmente pertence a uma família monoparental, no nível 3 da escala de Graffar, ${ }^{7}$ cujo agregado inclui a própria e o seu filho de 15 meses.

A Judite é filha de pai ex-dependente de álcool e de mãe toxicodependente, abandonada pela mãe alguns dias após o parto, ficando a cargo da avó paterna e a partir dos 12 anos com o pai. Como antecedentes pessoais iniciou consumos de haxixe-marijuana aos 13 anos de idade e manteve consumos de tabaco, haxixe, heroína e cocaína dos 15 aos 22 anos, estas duas inaladas e injectadas, bem como manteve uma ingestão frequente de alucinogénios. Refere actualmente consumos de haxixe, quantificado em 3 doses/dia, e de tabaco de cerca de 4-5 cigarros/dia.

Tem infecção VIH ${ }_{1}$ conhecida desde o ano de 2003 (22 anos de idade) e, por aumento da carga viral, iniciou terapêutica tripla anti-retroviral em 2007 com tenofovir, emtricitabina e efavirenz, seguida em consulta de Infecciologia. Fez contracepção oral de forma irregular. Tem Beta-Talassémia minor diagnosticada em 2000, seguida na consulta deHematologia, com uma frequência semestral. Refere otites externas de repetição no passado, com seguimento em consulta anual de Otorrinolaringologia.

O namorado, Pedro (nome fictício), desempregado, está a frequentar um curso profissionalizante durante a semana em local distante. Tem hábitos tabágicos e consumos diários de cannabis inalado. É seropositivo para o $\mathrm{VIH}_{1}$ e asmático.

Contexto obstétrico: Primeira gravidez não planeada, mas desejada, pelo que recorreu ao centro de saúde com 8 semanas de amenorreia. Foi enviada à consulta de Alto Risco do Hospital de Referência e continuou a ser vigiada em consulta bimensal pelo médico de família, consulta mensal de Obstetrícia para Gravidez Adicta e consultas de Infecciologia. Fez consulta de diagnóstico pré-natal, onde realizou testes bioquímicos de rastreio que concluíram existir uma baixa probabilidade de risco de cromossomopatias. Iniciou lamivudina, zidovudina, lopinavir e norvir, ferro, ácido fólico e Fantomalte ${ }^{\circledR}$ (preparado em pó rico em glúcidos) na gravidez, e suspendeu os outros fármacos. Durante este período ainda foi acompanhada pela Assistente Social, pela Psicologia da Associação Abraço e pela Psiquiatria.

Por sua iniciativa, às 8 semanas de gestação suspendeu os consumos de drogas, excepto de haxixe, que manteve na quantidade de 3-4 doses/dia e de tabaco de cerca de 10 cigarros/dia. Durante a gravidez a Judite terminou o $12 .^{\circ}$ ano, na área de Ciências Sociais e Humanas. Esteve a viver com um tio paterno dos 25 aos 26 anos, planeando-se que sairia de casa deste, por motivos de casamento do tio, e passaria a viver com o namorado em casa própria, o que aconteceu às 30 semanas de gestação. Recebeu o subsídio de gravidez a partir da 13. a semana de gestação e o subsídio de parto. Teve apoio do rendimento mínimo até ao parto e durante os primeiros 12 meses de maternidade.

O parto foi de termo, induzido às 38 semanas de gestação, tendo sido previsto um parto eutócico por vontade materna e cargas virais indetectáveis, mas a não progressão pelo canal de parto motivou a realização de uma cesariana. Fez AZT intra-parto e retomou a terapêutica retroviral da gravidez. Um mês depois do parto altera-se a medicação para tenofovir, emtricitabina e efavirenz.

História actual: Paulo (nome fictício), recém-nascido com $3345 \mathrm{~g}$ de peso, $49 \mathrm{~cm}$ de comprimento, 34.5 de perímetro cefálico, índice de Apgar de 9 e 10 ao $1 .^{\circ}$ e $5 .^{\circ}$ minutos de vida, respectivamente. Iniciou AZT no primeiro dia de vida e co-trimoxazol às 6 semanas, segundo o protocolo de prevenção da transmissão vertical doVIH da Sociedade Portuguesa de Pediatria, ${ }^{8}$ que manteve até aos 4 meses de idade, tendo sido seguido em consulta de Infecciologia até 
receber alta aos 20 meses de idade. As análises para pesquisa do VIH (PCR para DNA de VIH1) no recém-nascido/lactente foram sucessivamente negativas (dia 0 , dia 11 , aos $2 \mathrm{M}, 4 \mathrm{M}, 6 \mathrm{M}, 18 \mathrm{M}$ ) e aos 4 meses de idade efectua a vacinação com BCG. A electroforese das hemoglobinas não mostrou alterações. Desde a alta hospitalar teve os seguintes apoios sociais: leite, fraldas, e de uma amiga que doou vestuário de bebé e cadeirinha de transporte, pai e vizinha que por vezes tomavam conta da criança.

Inicialmente o pai do Paulo acompanhou a criança à consulta de Saúde Infantil, alternando com a mãe, mas posteriormente, por separação dos pais, a criança ficou a cargo unicamente da mãe.

De realçar episódio único de bronquiolite aos 11 meses de idade. Por febre e dificuldade respiratória a mãe recorreu oportunamente ao Serviço de Urgência onde foi aconselhada a proceder a medidas terapêuticas gerais.

Dos 6 aos 12 meses de idade apresentou um ligeiro atraso do desenvolvimento psicomotor a nível da linguagem e motricidade, pelo que se referenciou a consulta de Desenvolvimento. O Paulo tem actualmente 15 meses. Ainda não anda, nem se põe de pé com apoio e os sons são guturais. As avaliações somatométricas apresentaram poucas variações dentro dos Percentis 50 a 90. O restante exame objectivo, que incluiu um rastreio da acuidade visual e acuidade auditivas, estava bem. À data a criança ainda não foi chamada para a consulta de Desenvolvimento (provavelmente por existirem casos mais graves e por existir um grande tempo de espera para a consulta), mas discutiu-se o caso em Consultadoria de Pediatria, em conjunto com a Assistente Social.

\section{COMENTÁRIO}

Este caso é paradigmático da multiplicidade de problemas frequentemente associados ao consumo de drogas na gravidez. A actuação conjunta da Pediatria hospitalar, Médico de Família e Serviço Social é fundamental.

Gostaríamos de discutir alguns pontos-chave deste caso, abordando o ponto de vista de cada um dos elementos desta equipa multidiscilplinar.

1. Sendo os consumos durante a gravidez apenas de haxixe, uma droga considerada «leve», existe probabilidade de após o parto a criança manifestar uma síndrome de abstinência?

\section{Pediatra:}

O haxixe é sempre uma droga potencialmente prejudicial ao feto e à futura criança, para além de que interfere ne- gativamente na interacção mãe-filho. A síndrome de abstinência também se pode associar a esta substância. Dependendo da quantidade diária de canabinóides consumida pela grávida, o recém-nascido pode manifestar mais ou menos sintomas. O haxixe actua nos receptores canabinóides promovendo o aumento dos níveis de dopamina, o que provoca nos indivíduos uma sensação de bem-estar, relaxamento e também uma diminuição das memórias de curta duração. Está associado a alterações da aprendizagem, pensamento e percepção.,

Tem ainda um efeito analgésico tanto na mãe como no feto. Reduz a oxigenação durante a gestação e diminui o volume do Sistema Nervoso Central fetal. O haxixe é muito lipossolúvel e tem uma lenta eliminação do corpo, pelo que a exposição fetal se encontra potenciada. ${ }^{2,3}$

No recém-nascido existe uma ausência súbita da droga, podendo existir uma síndrome de abstinência. O recém-nascido pode manifestar um conjunto de sinais e sintomas de doença, como tremores, diarreia, etc. Esta criança pode ter ou não apresentado uma síndrome de abstinência.

\section{Médico de família:}

Parece não ter sido diagnosticado um síndrome de abstinência. Não há referência no Boletim de Saúde Infantil a qualquer intercorrência pós-parto e tanto o recém-nascido como a mãe saíram da Maternidade ao $5 .^{\circ}$ dia pós-parto, o que corresponde ao tempo habitual após uma cesariana.

2. Quando a criança nasce, como se pode diagnosticar uma síndrome de abstinência?

Pediatra:

A síndrome de abstinência deve ser suspeitada quando na história materna apuramos o consumo de drogas ou metadona durante a gravidez, pesquisando substâncias na urina e sangue e utilizando depois escalas de observação do recém-nascido.

A escala que mais utilizamos é a escala de Finnegan ${ }^{9,10} \mathrm{e}$ baseia-se na observação de sinais e sua pontuação. Os sinais que mais pontuam são o choro gritado, o sono curto e fragmentado, os tremores, as escoriações múltiplas no nariz, queixo, cotovelos, joelhos e pés, a hipertermia, a sudorese profusa, as crises esternutatórias constantes, uma frequência respiratória acima de 60 por minuto, uma sucção descoordenada que dificulte a alimentação, vómitos em jacto e diarreias profusas. Com uma pontuação igual ou superior a oito em três observações consecutivas ou igual ou superior a 12 em duas observações consecutivas, dever-se-á considerar o tratamento farmacológico. As escalas depois são apli- 
cadas nas reavaliações para seguimento da criança.

A evolução da sintomatologia quando ocorre é em crescendo, de início (geralmente entre o $1 .^{\circ}$ e o $3 .^{\circ}$ dias de vida) são os tremores, por volta do $10 .^{\circ}$ dia começam as convulsões, sendo que o Síndrome dura em média duas semanas. Os sintomas sub-agudos como a irritabilidade, hipertonia e alterações do sono e da alimentação poderão persistir 4 a 6 meses. ${ }^{4,11}$

\section{Médico de família:}

A mãe refere que a criança chorava muito, estava agitada e tinha cerca de 4-5 dejecções diárias, líquidas a pastosas, contudo poderiam ser as fezes normais do lactente. A pontuação na escala de Finnegan foi sempre inferior a 8, de acordo com a referência materna, e a criança nunca fez tratamento algum durante a hospitalização.

\section{Pediatra:}

Pode ter ocorrido uma síndrome de abstinência mas mais fruste. $O$ diagnóstico de situações ligeiras é difícil pois sobrepõem-se a casos dentro da normalidade.

3. Existe um tratamento para a síndrome de abstinência logo após o parto?

\section{Pediatra:}

O tratamento não farmacológico de suporte é imprescindível e deve ser aplicado em todos os casos. O tratamento farmacológico é deixado para as situações mais graves. Vários fármacos têm sido utilizados, nomeadamente fenobarbital, morfina, metadona e diazepam, sendo a morfina o fármaco de primeira escolha para a privação a opiáceos. ${ }^{5,9,12}$

Neste caso clínico não me parece que tenham sido necessárias quaisquer intervenções farmacológicas.

Uma vez que o leite materno concentra estes tóxicos, por norma está contra-indicado. Esta é uma componente importante do tratamento, pois só assim temos a certeza de que a criança não tem drogas em circulação. Neste caso clínico a mãe refere um consumo diário de haxixe e nunca se sabe se de outras substâncias. Não deverá amamentar.

A excepção pode fazer-se para as mães em programa de metadona. Nestes casos o aleitamento materno não está contra-indicado. ${ }^{4}$ A excreção de metadona no leite materno promove um «desmame» gradual da droga pelo recémnascido, que por vezes não chega a ter manifestações de abstinência ou estas são mais frustres. No entanto, o consumo ilícito das mães toxicodependentes hospitalizadas é sempre ocultado, o que dificulta o cálculo correcto das doses, sendo que existem hospitais que preferem desaconselhar o aleitamento materno em todas as situações.
O tratamento de suporte é favorecido desde logo por toda a equipa médica e de enfermagem. Infelizmente ainda não temos as óptimas condições no Hospital para proporcionar ao recém-nascido o melhor ambiente possível. O ambiente favorável deverá ser tranquilo, isento de ruídos desnecessários e de estímulos luminosos. Deverão ser evitadas as manipulações e organizados os cuidados de modo a minimizá-las.

4. O contacto com estas substâncias durante a gravidez pode influenciar a criança quando ela for mais velha?

\section{Pediatra:}

Nas crianças mais velhas, filhas de mães toxicodependentes, poderão verificar-se alterações do desenvolvimento, do comportamento e do rendimento escolar. ${ }^{2,3,13}$ Aqui também depende da substância utilizada pela mãe e do número de doses.

As crianças são influenciadas, pelo efeito prejudicial da droga durante a gravidez, mas também por toda a vivência materna durante a permanência in utero e pelo ambiente familiar durante o desenvolvimento posterior da criança.

\section{Médico de família:}

E de facto, a criança mostra um ligeiro atraso do desenvolvimento psicomotor nesta fase. Só com um ano começou a gatinhar e presentemente ainda não se põe de pé. Os primeiros sons não foram o vulgar palrear incompreensível; mas foi antes um som gutural. Por isso foi apresentada nesta reunião e referenciada à consulta de Desenvolvimento do Hospital de referência. A etiologia do atraso do desenvolvimento nestes casos pode ser multifactorial, e em adição podem existir cuidados peri-natais deficientes, carências nutricionais, menor vinculação mãe-filho, etc.

5. E depois da alta hospitalar, que atitudes poderão ser tomadas perante a Judite e o filho? Qual o papel do Médico de Família?

\section{Médico de família:}

Relativamente à mãe devem ser prestados os cuidados habituais de promoção da Saúde de adulto e diagnóstico precoce de doença, incluindo discutir os aspectos positivos enegativos do consumo de substâncias ilícitas ou de tabaco e promover informação acerca de contraceptivos, discutindo a necessidade da sua utilização. As abordagens cognitivo-comportamentais individuais e em grupo mostraram ser eficazes para a redução do uso de cannabis. ${ }^{14}$ Para melhorar a competência materna podemos fornecer informação sobre os cuidados à criança nas diferentes etapas do desenvolvimento psicomotor e promover a vinculação, envol- 
vendo a mãe e a família alargada, bem como a vizinha amiga da Judite, ou outros. Sendo mãe solteira, o que confere grande vulnerabilidade à família, devemos acompanhá-la muito estreitamente através de consultas regulares ou até mesmo através de contactos telefónicos de suporte. Foi feita a articulação com a Assistente Social, para avaliar a rede de apoios já mobilizados e outros, tal como eventualmente referenciar à Comissão de Protecção de Crianças e Jovens (CPCJ) e com o Apoio Educativo da área para ser incluído num projecto de Intervenção Precoce. Sugeriu-se manter ligação da mãe a Psiquiatria ou a uma equipa de um centro de tratamento, bem como consultas de Psicologia, ao que a mãe revelou desinteresse. Disse-me a Judite: «O que me pareceé que a consulta de Psicologia é como ter uns bons amigos, e eu já estou a conseguir não fumar quando converso durante umas horas. Mas de manhã quando vou para o trabalho se não fumo nada, não consigo funcionar.»

\section{Pediatra:}

A Intervenção Precoce faz todo o sentido neste caso. Destina-se a crianças até à idade escolar que estejam em risco de atraso de desenvolvimento, manifestem deficiência, ou necessidades educativas especiais. Consiste na prestação de serviços educativos, terapêuticos e sociais a estas crianças e às suas famílias com o objectivo de minimizar efeitos nefastos ao seu desenvolvimento. Os programas de Intervenção Precoce devem, sempre que possível, decorrer no meio ambiente onde vive a criança. Habitualmente a intervenção inicia-se após a sinalização - geralmente feita pelos cuidados de saúde, creche/jardim infantil, ou pela própria família e pode iniciar-se entre o nascimento e a idade escolar.

6. Tenho uma óptima relação com a Judite, e o meu receio enquanto médica de família é de que seja quebrada a confiança entre nós, quando a CPCJ entrar na rede de apoio. Qual a sua opinião?

\section{Pediatra:}

Uma vez estabelecida uma relação de confiança entre o médico de família e a mãe, se lhe for explicado que o objectivo da CPCJ é avaliar e contribuir para o melhoramento das condições/competências sócio-familiares em conjunto com os pais (e não contra eles) por forma a proporcionar o melhor ambiente possível para o desenvolvimento do seu filho, a Judite entenderá e não verá com desconfiança a presença destes técnicos na sua casa.

7. Que apoio social pode ser oferecido a esta família? Assistente Social:

Em qualquer proposta de intervenção social a família deve ser tida em conta, e ela própria participar na concepção e na própria intervenção. Por outro lado, o trabalho da equipa multidisciplinar, a articulação entre os seus membros, e a partilha de todos os pontos de vista também é de extrema importância para a resolução de situações de carácter social.

Assim sendo, e após o levantamento cuidado de todas as necessidades sentidas pela mãe da criança e detectadas pela Assistente Social, no que respeita tanto a esta mãe como à criança - Diagnóstico Social - devem ser desencadeados vários procedimentos, a saber (Figura 1):

No que se refere à criança, e como já foi referido, deve sinalizar-se o caso à Comissão de Protecção de Crianças e Jovens (CPCJ) da área de residência com o intuito dos profissionais da Comissão acompanharem o crescimento e o desenvolvimento da criança, delineando-se o seu projecto de vida em colaboração com outros profissionais de outras entidades envolvidas e, naturalmente, com a mãe da criança.

Perceber, ao nível da Segurança Social, se a mãe já requereu o Abono de Família para Crianças e Jovens, a que o filho tem direito, para a auxiliar nos encargos da criança (alimentação, saúde, vestuário, educação, etc.).

Relativamente à actividade da Ama era importante tentar integrar a criança num estabelecimento escolar e recorrer à Ama no prolongamento, ou seja, desde que a creche encerra até que a mãe regresse a casa, de forma a fomentar a interacção e o contacto com outras crianças de forma mais estruturada.

Por fim, e uma vez que há referência de que esta mãe terá sido acompanhada pela Ajuda de Berço aquando do nascimento da criança, deve também ser estabelecido um contacto funcional com esta instituição para complementar eventuais lacunas do diagnóstico social, uma vez que já têm conhecimento do caso há mais tempo.

Quanto à progenitora da criança em causa, existem também aqui vários pontos que devem ser trabalhados.

Uma vez que se trata do primeiro filho, e que o quadro da família onde nasceu não é o desejável, é necessário tentar perceber se haveria a necessidade de trabalhar as competências parentais, e se sim, articular com instituições locais que desenvolvem esse trabalho, e sobretudo, também, com a CPCJ.

Face à sua situação de empregabilidade, tendo em conta que não é estável, e que acaba por ser um pouco precária, pode ser encaminhada para uma instituição de apoio e promoção laboral, para que, caso apareça um emprego que 
ofereça melhores condições laborais, possa ter a oportunidade de responder.

Referenciar o caso para o Banco Alimentar Contra a Fome ou para programas de apoio alimentar que por vezes as autarquias promovem também poderia ser um contributo para colmatar as despesas com bens de primeira necessidade.

Ao nível da habitação, e através de visitas domiciliárias, perceber outras necessidades que possam existir, quer se trate de habitação camarária ou não, de forma a verificar as condições de habitabilidade desta mãe e desta criança.

\section{Caso sejam necessá-}

rias pequenas reparações ou aquisição de mobiliário, podese sempre contactar e articular com a Câmara Municipal.

Existe ainda outra área onde se pode intervir, que é ao nível da psicologia, caso a Médica de Família assim o entenda, pois estão disponíveis consultas de psicologia para qualquer utente do Centro de Saúde da área da residência. Entretanto este aspecto já foi realizado pelo Médico de Família.

Todas as medidas e os serviços mencionados são possíveis de accionar e visam a reinserção social desta mãe, de forma a reorganizar a sua vida, bem como impulsionar o crescimento saudável e cuidado desta criança com vista ao seu bem-estar e qualidade de vida.

Também as entidades e respectivos profissionais devem acompanhar progressivamente e de forma continuada esta família, até que tal se afigure necessário, trabalhando sempre e paralelamente a sua independência face aos serviços, apelando à sua capacidade de organização e à sua autono- mia, de forma a «desabituá-la» gradualmente do apoio dos mesmos.

Neste caso foi efectuada uma abordagem multidisciplinar no que se refere aos cuidados perinatais e ao acompanhamento da criança filha de mãe toxicodependente, com referenciações várias, incluindo, após a reunião com a Pediatra e Assistente Social, sinalização à Comissão de Protecção de Crianças e envio para início de intervenção precoce.

Os critérios de elegibilidade para intervenção precoce foram a existência de condições psicoafectivas e ambienciais, nomeadamente factores parentais com abuso de substâncias aditivas e desorganização familiar, que poderão dificultar com elevada probabilidade a actividade e participação da criança e limitar as suas oportunidades de desenvolvimento. $^{15}$

O tratamento de suporte também foi instituído e reforçado pelo médico de família, bem como foi promovida a ligação mãe-filho. 
O abuso de drogas em geral na gravidez e maternidade está associado a um desenvolvimento prejudicial da criança, fundamentado em vastas e sólidas publicações. Contudo, existem ainda poucos trabalhos de investigação ou estudos prospectivos relacionados com a dependência de canabinóides na maternidade. Há ainda muito lugar no futuro a um aprofundar de conhecimentos sobre a evolução natural dos filhos de mães dependentes desta droga dita «leve» e a um aperfeiçoamento de orientações diagnósticas e de tratamento.

Nota: Os nomes própios são fictícios por forma a respeitar o anonimato.

\section{REFERÊNCIAS BIBLIOGRÁFICAS}

1. WHO. Management of substance abuse - The global burden; 2002. Disponível em: http://www.who.int/substance_abuse/facts/global_burden/en/index.html [acedido em 24/06/2011].

2. Iverson L. Long-term effects of exposure to cannabis. Curr Opin Pharmacol 2005 Feb; 5 (1): 69-72

3. Karila L, Cazas O, Danel T, Reynaud M. Conséquences à court et long terme d'une exposition prénatale au cannabis. J Gynecol Obstet Biol Reprod 2006 Fev; 35 (1): $62-70$.

4. Palminha JM, Lucas AM, Vasconcelos MT, Manteigas MZ, Mano MA, Costa MH, et al. Os filhos dos toxicodependentes - novo grupo de risco bio-psico-social. Porto: Asa Gráfica; 1993. p. 151-5.

5. Serrano A, Mendes MJ, Coelho A. Negrão F, Pita O. Recém-nascido de mãe toxicodependente. Consensos Nacionais de Neonatologia. Lisboa: Sociedade Nacional de Pediatria; 2004. p. 181-3.

6. National Research Council (US) Commitee on Earlychildhood Pedagogy. Eager to learn-educating our pre-schoolers. Washington, DC: NRS; 2000. p. 308

7. Graffar M. Une méthode de classification sociale d'échantillon de la population.
Courier; 1956; 6: 455-9

8. Secção de Neonatologia da Sociedade Portuguesa de Pediatria. Protocolo de Prevenção da Transmissão do Vírus da Imunodeficiência Humana (VIH). Acta Pediatr Port 2008 Mar-Abr; 39 (2): 79-83.

9. Galanter M, Kleber HD.American Psychiatric Association, Practice Guideline for the Treatment of Patients with Substance Use Disorders. American Psychiatric Publishing; 2010 Disponível em: http://www.psychiatryonline.com/pracGuide/ pracGuideChapToc_5.aspx [acedido em 21/05/2010].

10. Wang M. Perinatal drug abuse and neonatal drug withdrawal; 2010. Disponível em: http://www.emedicine.medscape.com/article/978492-overview [acedido em 20/05/2010].

11. Finnegan L. Neonatal abstinence syndrome: assessment and pharmacotherapy. In: Rubaltelli FF, Granti B, editors. Neonatal Therapy: an update. Amsterdam: Elsevier Science; 1986. p. 122-46.

12. Johnson K, Gerada C, Greenough A. Treatment of neonatal abstinence syndrome. Arch Dis Child Fetal Neonatal Ed 2003 Jan; 88 (1): F2-5.

13. Budden SS. Intrauterine exposure to drugs and alcohol: how do the children fare? Medscape Womens Health 1996 Oct; 1 (10): 6.

14. The Cochrane Collaboration. Psychotherapeutic interventions for cannabis abuse and/or dependence in outpatient settings (review); 2008. Disponível em: http:// www.cochrane.org/reviews/en/ab005336 [acedido em 22/5/2010].

15. Diário da República (Portugal). Dec-lei n²81/2009, de 12 de Outubro - artigo $3^{\circ}$

\section{CONFLITOS DE INTERESSE}

Os autores declaram que não existem conflitos de interesses.

\section{ENDEREÇO PARA CORRESPONDÊNCIA}

Cristina Nunes

Alameda da Encarnação, 11

1800-187 Lisboa

ccrrn@hotmail.com

Recebido em 25/06/2010

Aceite para publicação em 22/04/2011

\section{ABSTRACT}

\section{MATERNAL DRUG USE DURING PREGNANCY AND INFANCY - THE IMPORTANCE OF A MULTIDISCIPLINARY APPROACH}

Introduction: Drug use in pregnancy and infancy is a serious problem. In particular, the use of marijuana by the mother is not harmless. It may be associated with a withdrawal syndrome in the newborn and may affect the development of older children.

This article describes a multidisciplinary approach to maternal drug use, providing advice to the family physician in dealing with affected children and increasing interest in the effects of drug addiction on the mother-child relationship.

Description: We present the case of a pregnant woman affected by marijuana use and the human immune deficiency virus (HIV). The pregnancy was unplanned, but desired and monitored. The child presented with a delay in psychomotor development of 3 to 6 months. The case was managed by a family physician together with a pediatrician and a social worker. Comment: A multidisciplinary approach is recommended in these cases through timely referral. Provision of support for the mother is always appropriate and should be given early. Promotion of a functional family environment along with the surveillance of the child protection services, educational interventions during pregnancy and in the first months of life of the child are of value in aiding child development. This type of care is possible by the family doctor.

Keywords: Behavior Addictive; Neonatal Abstinence Syndrome; Early Intervention; Marijuana Abuse. 